\title{
Using PDA for undergraduate student incidental vocabulary testing
}

\author{
YANJIE SONG \\ Faculty of Education, The University of Hong Kong \\ Room 109, HOC Building, HKU, Pokfulam Road, Hong Kong \\ (email:songyj@hkusua.hku.hk)
}

ROBERT FOX

Faculty of Education, The University of Hong Kong, Room 111C, Runme Shaw Building, HKU, Pokfulam Road, Hong Kong

(email: bobfox@hku.hk)

\begin{abstract}
Recent studies have explored English vocabulary learning in environments where students used mobile technologies for prescribed vocabulary learning tasks, or tested designed personalized learning systems to enhance student vocabulary learning for short periods of time in language related courses. Dictionary use via mobile devices has mostly been used for referential purposes. Referential use refers to applications that provide student access to content such as dictionaries, e-books, etc. at places where learning activities occur, taking advantage of the portability and mobility of mobile devices. Research on free student use of mobile devices to foster incidental vocabulary learning in non-English courses remains scant, and no in-depth studies have been carried out to investigate the value of dictionary use on mobile devices for incidental vocabulary learning in higher education. This one-year multiple-case study investigated undergraduate students' dictionary and other uses of Personal Digital Assistants (PDAs) to enhance their incidental vocabulary learning in an English as a Medium of Instruction (EMI) university. The research findings show: (a) the students made various uses of the PDA to improve their vocabulary learning, namely, referential, situated, constructive, reflective, explorative and conversing uses, (b) the students adopted integrated uses of the tools on the PDA and the computer for their incidental vocabulary learning, and (c) the integrated use of the PDA and the computer shaped the vocabulary learning activities and vice versa. These research results indicate that PDAs can be used in more flexible, novel and extended ways for English as a Foreign Language (EFL) vocabulary teaching and learning in higher education, taking student needs and contexts into consideration.
\end{abstract}

Keywords: Dictionary use, EFL, incidental vocabulary learning, mobile technology, PDA use, referential use

\section{Introduction}

English learning is important for university students in non-English speaking countries, especially those students from universities where English is a medium of instruction 
(EMI). Vocabulary learning is crucial for English learning because vocabulary constitutes the basic building blocks of English sentences (Nation, 2001). Research into vocabulary learning for English as a foreign language (EFL) students has been prominent. Many research findings show that a poor vocabulary frequently leads to incorrect inferences or misunderstanding of the content when reading English materials (Gu, 2003; Huang, 2007; Nation, 2001). The lack of vocabulary is the main barrier for understanding English materials. Vocabulary learning strategy literature shows that the use of the dictionary has a positive effect on students' vocabulary learning in terms of their language course studies (Gu, 2003; Laufer \& Hill, 2000; Nation, 2001). Students need to improve their English for their academic studies. One study shows that experienced dictionary users among international undergraduate students studying in an EMI university in the UK preferred to use more than one dictionary on a regular basis to improve their incidental vocabulary learning for their academic study (Nesi \& Haill, 2002). However, in the digital age, few students bring along a thick dictionary to class or places of study. They may bring a handheld electronic dictionary, or a mobile device with downloaded dictionaries such as a mobile phone or a Personal Digital Assistance (PDA). Mobile devices have been increasingly developed, designed and used to 'ultimately support a lifetime of personal and social enrichment' that can support education (Roschelle, Sharples \& Chan, 2005: 161). How do EFL students make use of the PDA as a tool on their own to help with their incidental learning of vocabulary in the course of pursing their degree in higher education? Research in this area remains limited. However, understanding EFL students' perceptions of PDA use for incidental vocabulary learning is important. It will help the EFL researchers and teachers understand students' needs and strategies in coping with vocabulary difficulties in their academic reading. This, in turn, will help improve mobile technology educational practices and support for student lifelong learning.

The following section of this paper reviews incidental vocabulary learning literature and identifies the research framework, followed by the research method adopted in a longitudinal multiple-case study. Research results are then presented, and implications relating to the results are discussed.

\section{Literature on English vocabulary learning for EFL students}

\subsection{Incidental vocabulary learning}

Vocabulary learning activities generally fall into two types: intentional and incidental learning of vocabulary (Nation, 2001). The former refers to activities that aim at vocabulary development predominantly. When vocabulary is learned predominantly through extensive reading, with the student guessing at the meaning of unknown words that do not have a predominant focus on vocabulary development, the activities are called incidental learning of vocabulary (Huckin \& Coady, 1999; Nakata, 2008). Incidental learning creates opportunities for inferring word meaning in context, enables vocabulary acquisition and reading at the same time, and is more individualized and student-based because the vocabulary being acquired is dependent on the student's own selection of reading materials (Huckin \& Coady, 1999). However, studies have revealed that incidental learning of vocabulary may lead to such problems as incorrect 
inferences, and lack of retention (Huang, 2007). This is due to the fact that correct inference of word meanings depends on the comprehension of $95-98 \%$ of the words in the text (Huckin \& Coady, 1999). According to Laufer's survey (1992), the reader's understanding of $95 \%$ of familiar words and $2 \%$ of unfamiliar words is necessary for text comprehension. The problem with guesses may be due to the fact that unlike native speakers, EFL students often lack the word knowledge from context and do not use active reading strategies (Grabe \& Stoller, 1997). They need to be able to have constant access to word related resources such as dictionaries to help resolve problems in their academic study.

\subsection{MALL in terms of incidental vocabulary learning}

Some studies have attempted to use computer-based dictionaries to improve EFL students' incidental English vocabulary learning in language courses (e.g., Hill \& Laufer, 2003). Hill \& Laufer's (2003) research findings showed that the use of computer-based dictionaries could trigger more incidental vocabulary related learning activities for Chinese EFL university students (Hill \& Laufer, 2003). In recent years, studies on mobile technology assisted vocabulary learning are on the rise, taking advantage of the unique characteristics of immediacy, flexibility, portability, context sensitivity, social interactivity, connectivity and individuality (Crowe \& van't Hooft, 2006; Klopfer, Squire, \& Jenkins, 2002; Kukulska-Hulme, 2007). These studies have experimented with improving students' vocabulary learning in an environment where students used mobile technologies for prescribed vocabulary learning tasks, or tested designed personalized learning systems to enhance students' vocabulary learning in the short term in language related courses (Chen \& Chung, 2008; Song, in press; Stockwell, 2007; Thornton \& Houser, 2005). Dictionary use via mobile devices has often been considered simply a reference for students that is not assumed to induce other vocabulary learning activities (Clough, Jones, McAndrew, \& Scanlon, in press; Patten, Arnedillo-Sanchez, \& Tangney, 2006). The concerns regarding whether dictionary use of the PDA will be referential only for students' incidental vocabulary learning across their academic studies in higher education, and what other uses of the PDA can help students' incidental vocabulary learning activities are unknown. This empirical research was an attempt to fill this gap. It aimed at investigating students' free use of mobile devices - PDAs to foster their incidental vocabulary learning in terms of dictionary and other uses at an EMI university in Hong Kong from the perspective of the students. The research questions are:

1. What dictionary use of the PDA did the students make to support their incidental learning of vocabulary?

2. How did dictionary use of PDA help the students with their incidental learning of vocabulary?

3. What other uses of PDA did the students make to support their incidental vocabulary learning?

4. How did these other uses of the PDA help the students with their incidental learning of vocabulary? 


\section{Research methods}

Qualitative research through a multiple case study approach was adopted for a period of one year from April 2006 to March 2007, to gain a deeper understanding of the processes and outcomes of the PDA use in incidental vocabulary learning by the students, and to add confidence to the research findings (Merriam, 1998; Yin, 2003).

\subsection{Context}

According to Hulstijin, Hollander, and Greidanus (1996), intermediate and advanced EFL students enlarge their vocabulary to a great extent through incidental vocabulary learning. Students in EMI universities in Hong Kong are considered advanced EFL students as they passed certain English proficiency tests before being enrolled in these universities. These students often perceived a need to continue their study of English because most of the students' native language is Chinese. They need to read and understand lecture handouts, academic papers and books with the help of a dictionary throughout the course of pursing a Bachelor's degree. Laufer and Hill (2000) claimed that in EMI universities in Hong Kong, no instruction is given on the usage of dictionaries in their English enhancement courses. This provided opportunities for our research study to examine students' optimal lookup conditions in their incidental vocabulary learning.

\subsection{Student profile}

Three students were selected from first-year undergraduate students at a university on a voluntary basis (Patton, 1990). Three steps were involved in the student selection process. First, twenty-five potential students were chosen through an orientation seminar. The seminar aimed at introducing the research project to interested students who were aggregated through a mass email notice sent to all undergraduate students informing them of this seminar, and conducting a questionnaire survey in terms of student demographic information and their perceptions of computer technology use in relation to perceived usefulness and perceived ease of use. Second, focus group discussions were conducted to finalize the sampling process. Criteria were set up and coded for student selection based on the data collected through focus group discussions. The criteria for student selection were: positive attitudes towards technology use (to increase expectations that they would make good and extended use of the PDA); good self-management (to make sure that they could take good care of the device); staying in Hong Kong most of the time during the three-month summer vacation in the research year (for the convenience of data collection and to lessen the chances of device damage or loss); different disciplinary studies (to examine whether student PDA use varied from one disciplinary study to another, and what caused these differences); sex (to balance males and females); nationality/region (to examine whether students from different cultures used the device differently, and what caused these differences); and experience in using the PDA (to investigate whether experienced and inexperienced users varied greatly in terms of PDA use). A consent letter containing terms and conditions for participating in this project was given to the students in the discussions so that they had 
time to think whether they could accept the terms and conditions if they were chosen as participants. Finally, three students/cases were chosen for this research study. Their profiles are shown in Table 1. In this project, each student was provided with one $1 \mathrm{G}$ mini memory card and a PDA - a Dopod 818 Pro device for free use. Dopod 818 Pro is a wireless enabled device with both phone and PDA functionalities. A package of mobile phone telecommunication services was granted to students in order to encourage them to make more use of the device. In the university, free wireless access was available on campus and in university residential halls, where students could access the Internet using the device.

\subsection{Data collection and analysis}

Student electronic journals (e-journals), student artifacts and face to face (F-T-F) interviews were the main means of data collection over a period of one year. Retrospective interviews were also carried out based on the questions raised from student e-journals and artifacts submitted. Categorizing and contextualizing strategies were adopted to analyze the data collected at different stages (Maxwell, 1996).

The e-journals were concerned with students' reflection about their exploration and use of the PDA in their incidental vocabulary learning throughout their academic studies. A guide was provided for the writing of e-journals. These e-journals were intended to be used as 'introspective tools' in the research, as they could give the researchers access to 'the student's voices' (Nunan, 1992:118). Students were asked to submit their reflective e-journals to an online learning management system once a week for a year.

Artifacts in this research refer to screen captures or files that students made using the PDA. For example, Ann reported in her e-journal that she did an online search of a new word 'parity' via Google 'define' using the PDA, and then provided a screenshot of the notes to show us what she did (see Figure 1). This was considered Ann's artifact. Collecting student artifacts was considered unobtrusive for obtaining information about how students used the PDA (Savenye \& Robinson, 2004). From the artifacts that students submitted, the researchers were able to triangulate the uses of the PDA that students mentioned in their e-journals and interviews, and this enabled researchers to trace the changes in students' PDA use over time (Hodder, 2000).

Some educational research studies of the use of handheld devices have employed this technique as a means of data collection (e.g., Crowe \& van't Hooft, 2006; Swan, van't

Table 1 Student profile

\begin{tabular}{lclll}
\hline \hline Student* & $\begin{array}{l}\text { Age at the time } \\
\text { of the study }\end{array}$ & Major & $\begin{array}{l}\text { Year of } \\
\text { study }\end{array}$ & $\begin{array}{l}\text { Nationality at } \\
\text { time of study }\end{array}$ \\
\hline $\begin{array}{l}\text { Ann } \\
\text { Andy }\end{array}$ & 19 & Journalism & 1 & $\begin{array}{l}\text { Mainland Chinese } \\
\text { Evan }\end{array}$ \\
20 & Engineering & 1 & $\begin{array}{l}\text { Hong Kong permanent resident } \\
\text { Hong Kong permanent resident }\end{array}$ \\
\hline
\end{tabular}

*Pseudonyms are used to protect the students' identities. 


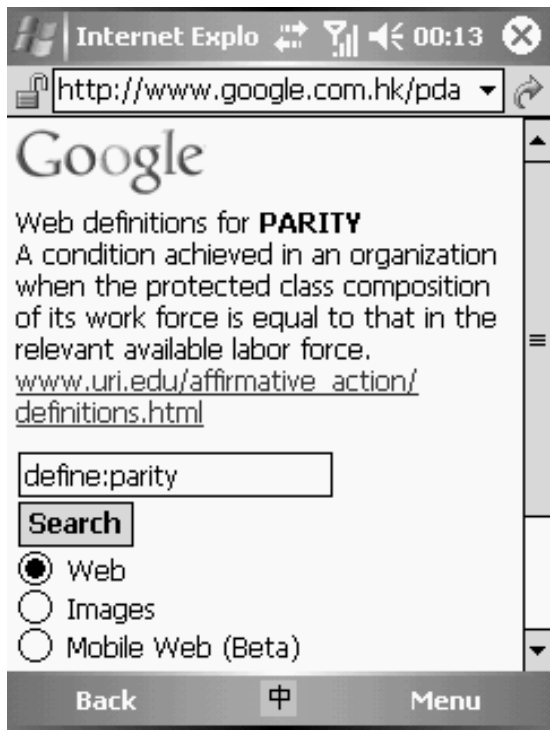

Fig. 1. Screenshot of Google define online search of the word 'Parity'

Hooft, Kratcoski, \& Unger, 2005). Guidance with an example of an artifact was provided for the students to prepare their artifacts.

Three semi-structured individual interviews were conducted after the students had used the PDA for one, six and twelve months respectively. The interview questions were centered on: (1) what dictionary use and other uses of the PDA did students make for their incidental vocabulary learning? (2) how did these uses help them in their learning? The analysis of the interview data helped the researchers gain a better understanding about how the PDA was used by the students and their perceptions of their PDA use. A list of uses emerged from each of the students. The interview was recorded, transcribed and checked by the students for accuracy. Each list of uses identified from the individual interviews was validated by the students' reflective e-journals and artifacts. Unclear descriptions or illustrations from the students' reflective e-journals and artifacts were clarified through retrospective interviews via emails, phone calls, or face-to-face discussions. The triangulated lists of uses from the students were further analyzed across cases for common attributes in exploring and using the PDA in their learning.

The data analysis underwent two stages. First, content analysis was used to categorize the data collected, adopting Nvivo qualitative analysis software. Student data sources were initially coded on the broader themes: dictionary use, other uses, and vocabulary learning. Coded themes of data were then recoded according to sub-themes. A constant comparative analysis was conducted on data to find sub-themes that initially emerged from student perceptions of their PDA use and their learning. A final list of sub-theme codes was placed in matrices by student names along with excerpts from student semistructured interviews, and e-journals. Afterwards, student artifacts and retrospective interviews were coded and put into the matrix by themes and sub-themes and student names in order to triangulate data. The triangulated sub-theme data were further 
analyzed for common themes that described common practices and thinking among the three cases in using the PDA for their study. Another sub-theme, common uses and perceptions, emerged from all three cases. The sub-themes of dictionary use included downloaded dictionary use and online dictionary use. The sub-themes of other uses included other PDA functional uses such as Notes, phone calls, email, MSN, etc. The sub-themes of learning included referential, data collection, situated, constructive, reflective, explorative and conversing uses. In the second phase of data analysis, a more descriptive method was adopted to contextualize PDA uses in each case to understand the 'true story' behind the uses for vocabulary learning in relation to the themes and subthemes.

\section{Results}

The following are results obtained from the analysis of the three cases. For the sake of clarity, the findings from the cases are presented individually. Then findings across the cases are also described. The research questions are answered in relation to what dictionary and other uses of the PDA students made, and how dictionary and other uses helped students' incidental vocabulary learning.

\subsection{Case 1: Ann}

Ann, from Mainland China, lives in a university hall. Majoring in Journalism, she took as many opportunities as possible to improve her English as she considered her English was not good enough. She had used a handheld electronic dictionary to help with her studies. As soon as she participated in this research project, Ann gave up using the electronic dictionary, and downloaded an English-Chinese dictionary, Dr. eye, onto the PDA. After a one-month trial, Ann had to pay for further use so she uninstalled this software, and found some freeware, Mdic, that consisted of a set of dictionaries. She downloaded the Oxford English-Chinese Dictionary. In an interview Ann stated:

I major in Journalism, I have to have a wide range of knowledge in English for my study. I liked the function of dictionary use on the PDA the most... The only software I downloaded to the PDA was a dictionary. I use it almost every day. (Ann, October 06, F-T-F interview).

Ann also took advantage of Internet access using the PDA. The following are the main uses that Ann made in her incidental vocabulary learning.

\subsubsection{Dictionary uses of the PDA: what and how}

- Downloaded dictionary on the PDA provided more opportunities for her to refer to unknown words in context.

Ann reported that the dictionary use increased her vocabulary retention by frequent exposure to unfamiliar words through repeated consultation, and helped solve problems in the reading materials such as the handouts and PowerPoint 
slides 'just-in-time' during lectures or self-study when a computer was not available.

- Downloaded dictionary on the PDA provided opportunities for her to understand unfamiliar words through discussion with classmates.

Ann reported that she often discussed with classmates unfamiliar words encountered during their study. She noted in an interview:

... in a Journalism lecture, my classmate encountered the word 'convergence', and asked me and others about its meaning. None of us knew the answer. So I consulted the dictionary on the PDA, and discussed with my classmates. We came to an understanding that the word in that context means 'a meeting place (of two lines)'. We all benefited from the dictionary use (Ann, September 2006, F-T-F interview).

\subsubsection{Other uses of the PDA: what and how}

- Online search using the PDA provided opportunities for her to gain deeper understanding of new words.

Ann reported that she usually used the downloaded dictionary on her PDA to look up unfamiliar words. But if she still could not quite understand the word, she preferred to do an online search via Google 'define' using the PDA (See Figure 1), or browse Wikipedia using a computer if a computer was available.

- The Notes function on the PDA provided opportunities for her to take down useful English expressions in context and reflect on the meaning and use afterwards.

Ann wrote down many expressions of English taken from lectures, talks or reading materials, and used them in her course work or project reports after reflection and reconstruction. She reported in her e-journal:

It was the annual high table dinner, Rita .., delivered a speech about how to face challenges. Her speech was so impressive... Because I didn't bring pen and paper to dinner, I used my PDA to take down some great quotes for future use in my writing (See Figure 2) (Ann, February 2007, e-journal).

- Downloaded materials on PDA provided the opportunity for her to review English words and expressions whenever she wanted.

In order to learn 'idiomatic' English, Ann downloaded passages and exercises from the book series 'New Concept English' to her PDA. She wanted to review and learn them by heart so that she could make free use of these expressions in her course work or project reports (See Figure 3).

\subsection{Case 2: Andy}

Andy is from the Department of Mechanical Engineering. He is a permanent Hong Kong resident, and lives at home. Andy used to consult dictionaries using a computer. In many cases, when he encountered vocabulary problems, and a computer was not 


AG| Notes
Sincerity and honesty is more than
any other.
Give yourself time to face a particular
time. It's normal you don't know how
to do.
Rule: whatever I do I will think wolud
it be benificial to the colleagues and
organization.
Not always prevail, instead failure
make us can handle better next time.
About long hair
Freedom of choice from the chamber
members
In accordance the hk law, they
selected be the member, but he
interrunted the nnrmal nrnress.
New

Fig. 2. Screenshot of the note about useful expressions taken in a talk

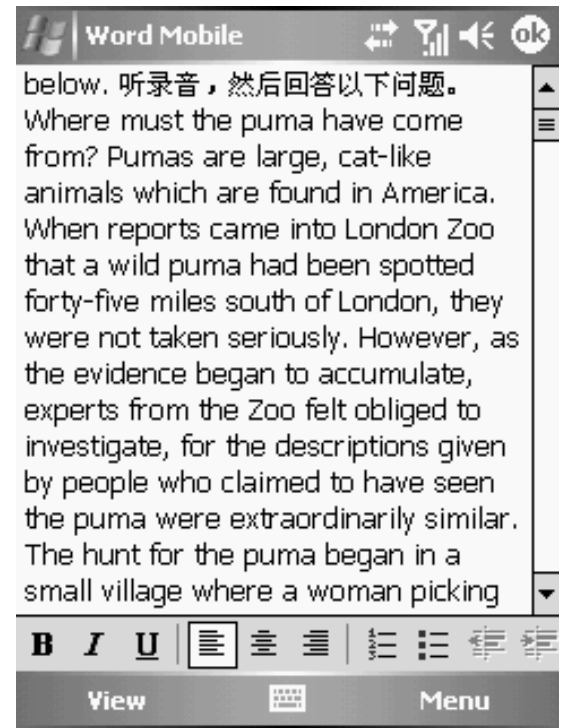

Fig. 3. Screenshot of an exercise excerpt from 'New Concept English'

available, he could not solve his learning problems in time. As soon as he joined this project, Andy found the Mebook consisting of varied dictionaries from the Internet. Because the file size of the Mebook was very large, he only downloaded a Professional English-Chinese Dictionary in his disciplinary study to the PDA. Andy also used the device to get access to the Internet for his vocabulary learning. The following are the main uses of PDA by Andy. 


\subsubsection{Dictionary uses of the PDA: what and how}

- Downloaded dictionary on the PDA provided opportunities for him to solve vocabulary problems during his revision of courses.

Andy reported that he usually looked up new engineering-related words and expressions from hardcopy handouts distributed by the lecturers before, during and after lectures, using the dictionary on the PDA. It was really helpful for his revision and reflection. Andy mentioned in his e-journal:

... When I am reviewing the course - Fluid Mechanics, I found many words I knew but the meanings used were very different from what I understood in this course. Thus, I needed to use the dictionary function to clarify the meanings. The PDA played a crucial role in such situations (Andy, June 2006, e-journal).

- Downloaded dictionary on the PDA provided opportunities for him to share vocabulary knowledge with peers in context.

Andy reported that when he worked in a group, they encountered unfamiliar words and expressions from time to time. In such cases, he would consult the dictionary, and then share the knowledge with the group.

- Downloaded dictionary on the PDA provided opportunities for him to learn the pronunciation of unfamiliar words.

Andy considered that his pronunciation of English was not proficient, so he downloaded the Professional English-Chinese Dictionary with a sound function, so that he could listen to the sound of the unfamiliar words. He said this helped him learn these words better (See Figure 4).

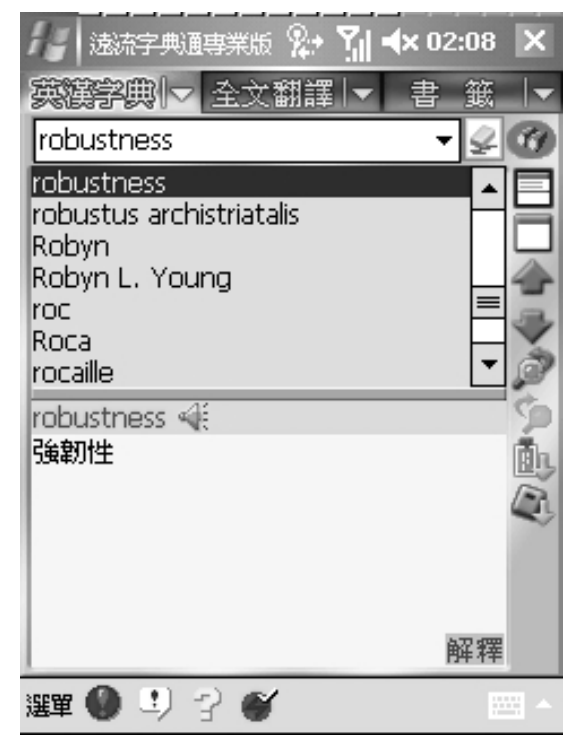

Fig. 4. Screenshot of the looked up word 'robustness' with pronunciation 
4.2.2 Other uses of the PDA: what and how

- $\quad$ The PDA provided opportunities for him to solve vocabulary problems by making phone calls to his classmates, or MSN chat with his friends.

Andy reported that when he could not find the unknown academic words in the dictionary on the PDA, he would call his classmates for their help. He also used MSN to chat with his friends to solve vocabulary problems. He reported that one day he arrived earlier at the airport when he was about to see a friend off:

It was the examination period, so I reviewed the handouts of the course 'Properties of Materials II'. I was not sure what 'ductile' meant in the statement 'The transition from ductile to brittle properties ...' as the Internet access in the airport was free-ofcharge, I logged into MSN and found my classmates there. I chatted with one classmate. He said that the word 'ductile' meant 'tough'. I was still not quite sure whether it was the correct interpretation, so I chatted with another classmate who was at home at that time. My classmate looked up the Professional Dictionary and provided two explanations of the word, one as 'flexible', another as 'tough'. The three of us joined a group for the discussion about which meaning was appropriate in this particular situation. We finally came to an agreement that 'tough' would be an appropriate meaning after we referred to the handouts again about related information provided... (Andy, November 2006, e-journal).

The PDA functions extended his collaborative vocabulary learning opportunities.

- $\quad$ Online dictionary accessed via the PDA provided opportunities for him to search academic terms online if those terms could not be found in the dictionary on his PDA.

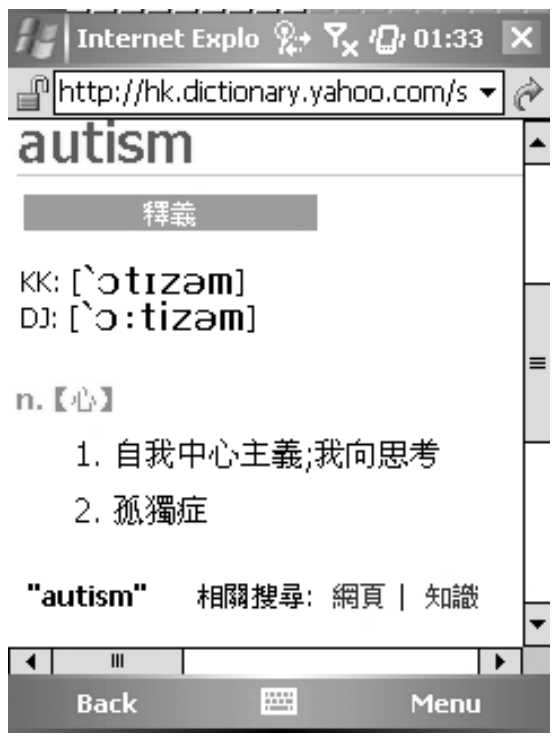

Fig. 5. Screenshot of 'Yahoo Online dictionary' search of the word 'autism' 


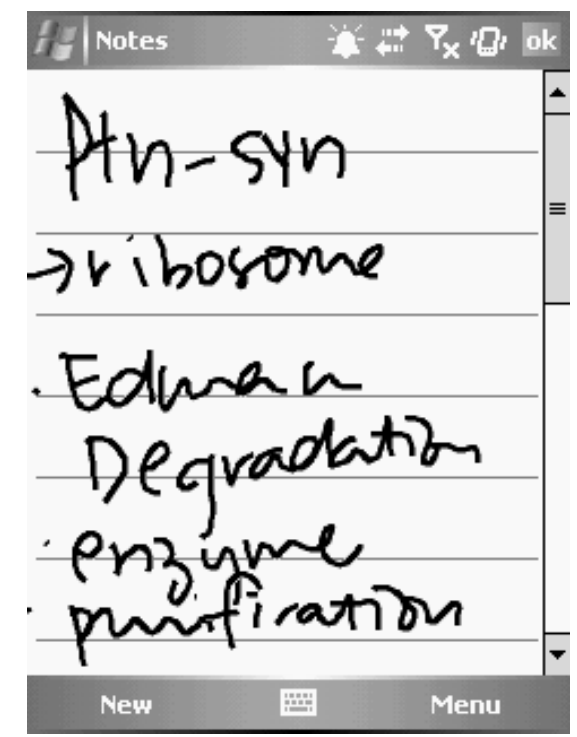

Fig. 6. Screenshot of the note about unfamiliar words taken during a lecture

Andy preferred consulting the downloaded dictionary on the PDA. However, if there were some terms that could not be found in the PDA, he would connect the PDA to the Internet and look up 'Yahoo Online Dictionary' (See Figure 5).

- Notes function on the PDA provided opportunities for him to take down unfamiliar words in context and re-read and look up meanings later.

Andy would take down unfamiliar words using the Notes function on the PDA during lectures when he could not find these words in the downloaded dictionary on the PDA, and other means of communication were not convenient in the lecture rooms (See Figure 6).

\subsection{Case 3: Evan}

Evan is from the Biotechnology Department. Though he is a local Hong Kong resident, he considered that his English was not proficient. Evan used dictionaries a lot. Before joining this project, he always carried a paper dictionary. He used the downloaded English-Chinese dictionary Dr. eye on his PDA after he joined this project. In the ejournals and artifacts he submitted, a large number of them were related to dictionary use using the PDA. He used dictionaries at home, in the university library, on campus, in transport, abroad during trips, etc. for vocabulary learning in his academic study. $\mathrm{He}$ mentioned in his e-journal:

With the downloaded dictionary on the PDA, I do not need to bring a traditional dictionary which is thick and heavy (Evan, May 2006, e-journal). 


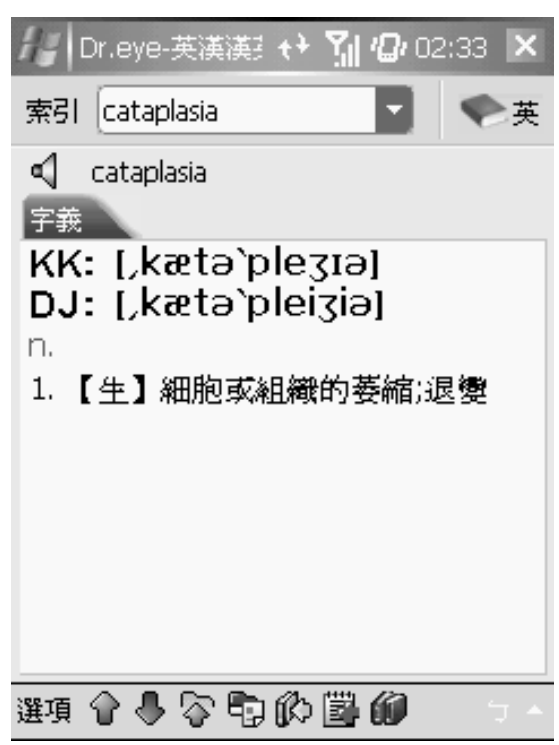

Fig. 7. Screenshot of the looked up word 'Cataplasia' from downloaded dictionary Dr. eye

The following are the main uses of PDA reported by Evan in his incidental vocabulary learning.

\subsubsection{Dictionary uses of the PDA: what and how}

- $\quad$ The downloaded dictionary on the PDA provided opportunities for him to consult academic vocabulary in context.

Evan reported that the dictionary, Dr. eye, played a key role during the situations when he encountered problems in reading academic papers, handouts or books. It was useful and convenient for his learning (See Figure 7). Evan mentioned in his e-journal:

I used my PDA as a dictionary to look up some biological terms whenever and wherever I needed (Evan, October 2006, e-journal).

- $\quad$ The downloaded dictionary on the PDA provided opportunities for him to improve his understanding of lectures, and help him do his assignments on overseas trips.

Evan reported that he used to guess new words and expressions during lectures if there was no dictionary available. With the PDA, he made fewer guesses, as guessing sometimes caused serious misunderstandings. Evan also mentioned that he got a ticket to the UK for a week. However, the deadline for the submission of his lab report and one essay were due in the same week. He chose to do his assignments using small chunks of time doing the reading and writing tasks on trains, planes, hotel, and buses, etc., during his trip. Whenever he had unfamiliar 


RG|Gmail
寄件日期: 8/5/06 09:01
Carolyn Muir
Re: Icarus, Wong Ho Yin
Dear Icarus,
The term "chiaroscuro" is generally
defined as the treatment and use of
light and dark within a painting. It goes
behind simply "modelling" which
refers specifically to using light and
shadow on an object or figure to
create the sense that it is 3
dimensional. So a discussion of an
artist's
chiaroscuro could refer to his modelling
of particular forms, as well as
his use of cast shadows on the
回覆

Fig. 8. Screenshot of email correspondance with a lecturer about the unfamiliar term 'chiaroscuro'

words or expressions that he was not sure of, he would use the dictionary on his PDA, which he found was really helpful.

- The downloaded dictionary on the PDA provided opportunities for him to learn the pronunciation of unfamiliar words.

Evan downloaded the dictionary, Dr. eye, which has a sound function. He reported that he frequently referred to this function. He felt that his pronunciation was considerably improved after the one-year trial, and practising the pronunciation helped him remember words better.

- $\quad$ The downloaded dictionary provided opportunities for him to help construct and proofread his course work.

Evan noted that when he was writing assignments, sometimes he would forget how to spell a word, or express ideas. In such cases, he would use synonymous expressions with the help of the dictionary on his PDA. Evan also constantly reported that he used the dictionary on his PDA to do proofreading after he completed essay writing.

\subsubsection{Other uses of the PDA: what and how}

- The PDA provided opportunities for him to get access to the Internet and write emails to his lecturers to solve problems relating to academic terms.

Evan mentioned one time when he had encountered the academic term 'chiaroscuro' that he could not understand even with the help of the online dictionary on his PDA. He then wrote an email to his teacher who responded immediately, explaining the term to him. He found this experience really enhanced his learning (see Figure 8). 
- The downloaded dictionary on the PDA could be used together with downloaded Wikipedia in his computer to get a better understanding of the meaning of words.

Evan mentioned that he downloaded Wikipedia into his desktop computer because looking up the downloaded Wikipedia was faster than doing an online search. He reported that he usually opened several files and Internet web pages on his desktop at the same time when he was working. If he wanted to look up a word, he had to open a new web page, and look for the Wikipedia website as he did not set the Wikipedia as the homepage. This would slow down the search process. Evan said 'I'd rather go directly to the downloaded website' (Evan, March, 2007, F-T-F interview). As the Wikipedia file size is about 4G, he could not download it to his PDA. He stated in an interview:

Because the explanations of the words in the downloaded dictionary on the PDA are quite simple, if I want to get deeper understanding of the words, I will access the Wikipedia downloaded to my desktop computer. It is faster than an online search (Evan, March 2007, F-T-F interview).

- Camera function on the PDA provided opportunities for him to capture photos with academic terminology for later memorization and reflection.

Evan used the camera function on the PDA to capture some pictures from books in the library or PowerPoint slides during lectures in relation to Biotechnology courses. He stated in an interview:

The camera function is very useful for me to take some useful photos for later use. It saved me time in taking down unfamiliar words. Besides, the pictures together with the words helped me memorize and reflect on their uses (Evan, March 2007, retrospective interview).

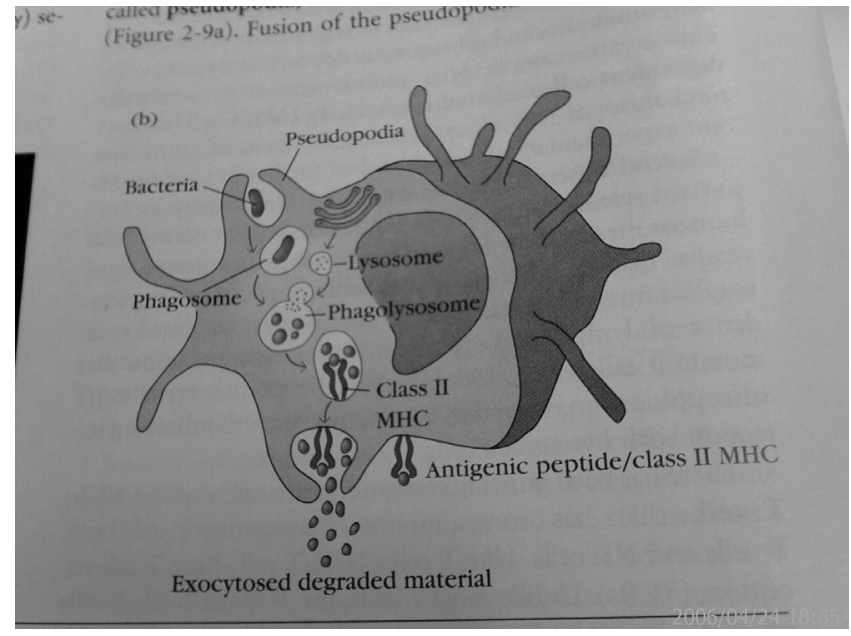

Fig. 9. Screenshot of the captured image with bio-chemistry terms 


\subsection{Common uses and perceptions of the PDA from Cases 1,2 and 3}

It is noted that perceptions from all of the three students are in some aspects quite similar, if not identical. They are as follows:

- Downloaded Dictionaries on the PDA provided opportunities for them to get faster access to unknown words than using a computer.

Ann reported in her e-journal that in her halls of residence, even when she was using her laptop to do some tasks, she would prioritize the use of the PDA to look up new words, as it was more convenient and faster than on a computer. She explained in a retrospective interview:

If I use the computer to consult an online dictionary, I usually have to open another window to copy and paste the key words in the online dictionary. Because my laptop processing speed is slow, it will further slow down the response rate (Ann, March 07, retrospective interview).

Evan shared a similar view:

Using the dictionary on the PDA to check the definition of some academic terms in papers and books is more convenient and faster than using a computer because the dictionary on the PDA does not require Internet connection (Evan, Oct 2006, F-T-F interview).

Evan further stated,

Even using a computer, I will use the dictionary on the PDA to look up new words because I am used to it. It is just at my finger tips (Evan, April 2007, retrospective interview).

\section{- Complementary use of the computer}

All of the students noted that they would use a computer as an alternative if they wanted to get detailed information or deeper understanding of certain words both on- and offline. They usually searched for information from Google 'define', Yahoo Dictionary, and Wikipedia online, or used the downloaded dictionaries or resources such as Wikipedia, Mdic, Mebook, Dr. eye and Powerword on the computer. These dictionaries and resources include much more detailed information than those on the PDA. Otherwise, they would choose to use the PDA. Andy stated in an interview:

It is not sensible for me to use the computer to look up new words encountered if I am not near to one... The PDA is so much more convenient ... It's with me all the time (Andy, March 2007, F-T-F interview).

In addition, all students felt more confident when they encountered problems during lectures or self-study and increased their efficiency. They could solve vocabulary 
problems in time during lectures, and better understood what the lecturers conveyed by using different searching options such as dictionaries both on- and offline. They also reported that the PDA helped them improve their vocabulary learning efficiency as well as their academic studies in general. Moreover, all the students had kept on using the PDA to consult unfamiliar words in participating in the one-year project. However, Andy reported that he used the PDA as a dictionary less in the second half of the year as he knew most of the academic terms in his disciplinary study. The other two students Ann and Evan did not make such claims.

\section{Discussion}

The research results indicate that students made a variety of PDA-based dictionary uses. These uses helped them in different ways with their incidental vocabulary learning, and enhanced their efficiency in their academic studies. In addition, other PDA uses, sometimes together with computer use, also helped enhance their vocabulary learning. The results of this three-case research provide a basis for developing a diagram of PDA uses for undergraduate students' incidental vocabulary learning during their academic studies. In addition, a diagram for integrated use of the PDA and the computer was developed. Finally, factors influencing these uses were also discussed.

\subsection{Diagram of PDA uses for incidental vocabulary learning}

Patten et al. (2006) categorize the use of referential material such as dictionaries and ebooks on mobile devices into a 'referential' function in terms of its mobile educational applications in formal learning situations (see Figure 10). They posit that referential applications generally do not go beyond information delivery. Based on this framework, Clough et al. (in press) further developed an informal mobile learning framework derived from their survey of web forum users in terms of mobile learning activities. They classify the use of referential materials into individual and collaborative referential activities (see Figure 11).

These frameworks shed some light on analyzing incidental vocabulary learning activities using PDAs in this study. However, in-depth analysis revealed that uses of referential materials via PDA rendered learning that is far more complex than these frameworks show. A diagram of the PDA uses derived from this study is presented in Figure 12.

\subsubsection{Referential uses}

Referential applications provided student access to content at places where learning activities occur, taking advantage of the portability and mobility of mobile devices (Patten et al., 2006). Such uses reported by the students include both individual and collaborative reference. Individual uses include the uses that the students made in referring to unknown words in the revision of academic reading materials such as handouts, slides, articles or books. Collaborative uses were concerned with the use of PDAs to look up unknown words, and share them with other students. This dictionary content access provided the students with a chance to learn vocabulary 'just-in-time'. 


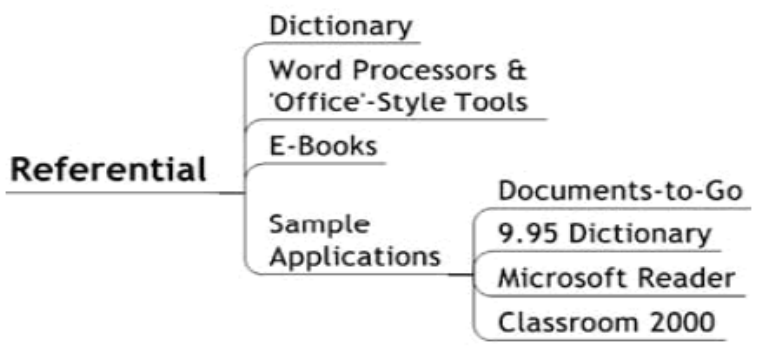

Fig. 10 Referential applications (abridged from Mobile Functional Framework by Patten et al., 2006)

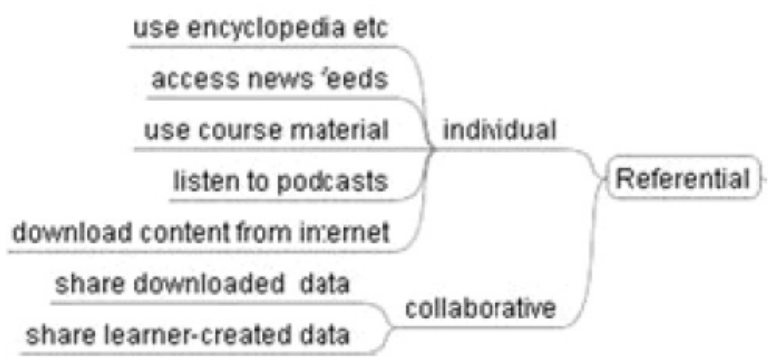

Fig. 11 Referential activities (abridged from Informal Mobile Learning Framework by Clough et al., in press)

\subsubsection{Data collection uses}

Data collection made use of the capability of the mobile device to record data and information about their environment (Clough et al., in press; Patten et al., 2006). Such uses described by the students include using Notes on the PDA to take down good 'English expressions' or capturing photos of some images in academic books or lecture slides for later review and reflection. Such data collection was usually not feasible, or problematic without the use of the mobile device (Patten et al., 2006).

\subsubsection{Situated uses}

Situated use refers to the mobile devices that offered opportunities for spontaneous, personal, informal, and situated learning for a socially situated practice (Lantolf, 2000; Shih \& Mills, 2007). The PDA uses are shifting the focus from smart planning to smart situated actions (Fischer \& Konomi, 2007). In this study, such uses students made included: finding out the meaning of academic terminology during lectures or tutorials when the lectures or tutors raised questions, and solving vocabulary problems when students used small chunks of time to do their academic assignments on buses, trains, planes and at hotels, etc.

\subsubsection{Constructive uses}

These uses refer to activities in which the students created or constructed 
knowledge individually or with others (Clough et al., in press). These uses allowed students the flexibility to represent their ideas as they saw fit, using the collected information or chunks of text or pictures (Jonassen, Hernandez-Serrano \& Choi, 2000). Students in this study constructed their academic writings to represent their ideas with words and expressions collected using the PDA, chose appropriate words in essay proofreading with the help of the dictionaries on PDA individually, or worked in concert with others to work out the meaning of words during their study. These uses afforded students a sense of involvement and vested interest that helped them sustain their intentions for further knowledge construction and learning (Jonassen et al., 2000).

\subsubsection{Reflective uses}

In reflective uses, the mobile device functioned as an intellectual partner with the student to engage and facilitate deep learning (Bourner, 2003; Jonassen et al., 2000). In this study, these uses were composed of individual and interactive reflective uses. In individual uses, students used dictionaries on the PDA to compare and confirm the meanings of academic terms when they revised their course materials. In addition, they reflected on their captured lecture notes or images using the PDA in order to better understand the vocabulary in the pictures, which not only aided students' vocabulary retention (Lai, Yang, Chen, Ho \& Chan, 2007), but also helped reflection when they were out of the learning environment. For interactive use, students used the downloaded dictionary with sound function so that they could consult the pronunciation of unfamiliar words for their own learning needs. Hill (1996) found that Chinese learners appeared to benefit from hearing the pronunciation of unfamiliar words as a means of retention. In this case, the PDA functioned as an intellectual companion for them to interact with.

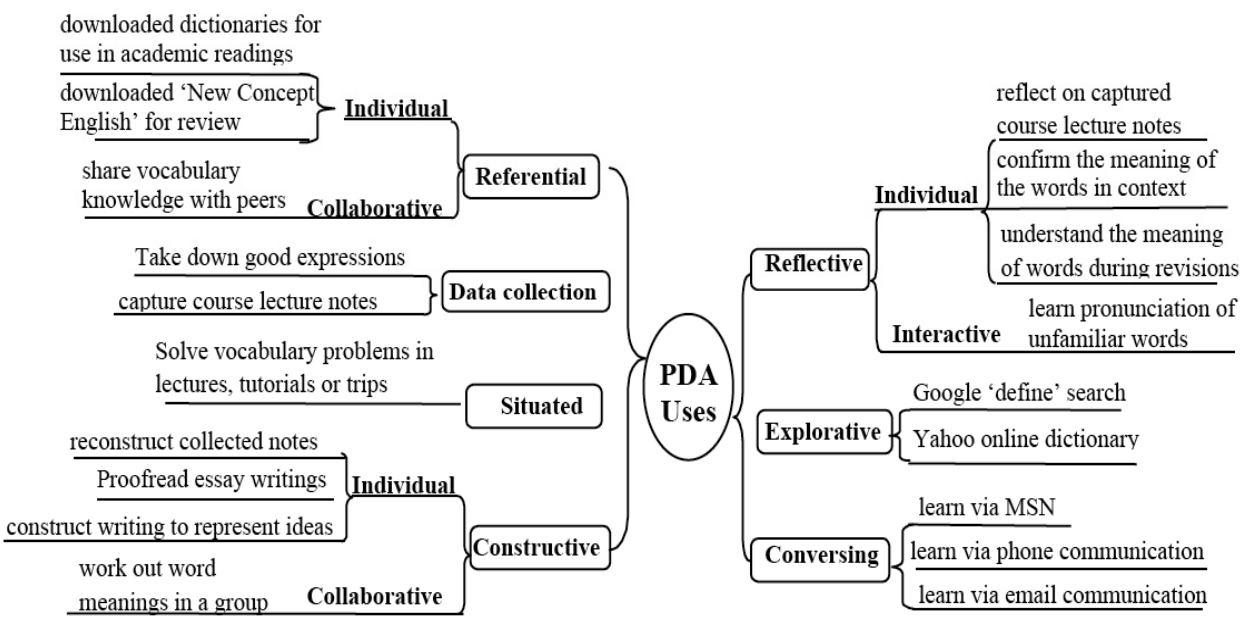

Fig. 12 Diagram of PDA uses for incidental vocabulary learning 


\subsubsection{Explorative uses}

In explorative applications, students searched and interpreted the information that was related to their learning needs (Jonassen et al., 2000). Students reported that whenever they wanted to get detailed explanations of certain words or academic terms, they would take the last resort by online searching via PDA or computer such as Google 'define' search, and the Yahoo online dictionary. Sometimes, they would use online or downloaded Wikipedia via a computer for the searching process. This process promoted meaning making by constantly fostering the students to interpret the information they were finding on website or downloaded resources in response to their intentional search, and to determine how relevant it was to their intended purpose (Jonassen et al., 2000). Rich information about the meaning of unknown words, explored positively, affects incidental learning (Hulstijin et al., 1996)

\subsubsection{Conversing uses}

Conversing use refers to the social interactions which led to learning made possible by taking advantage of the mobile device's unique characteristics of connectivity to the Internet and phone function (Jonassen et al., 2000; Jonassen, Howland, Moore, \& Marra, 2003). In this study, students used the PDA to solve vocabulary problems by making phone calls, through emails or MSN chat. Evan reported that he understood what 'chiaroscuro' meant after he wrote his teacher an email about it; and Andy mentioned how he and his classmates came to a common understanding of the word 'ductile' via MSN chat. In these applications, the PDA afforded 'conversation social interaction' for students to work together and socially reach a common understanding (Jonassen et al., 2000:122).

\subsection{Integrated use of the PDA and a computer}

It has to be noted that downloaded dictionaries on the PDA were not the only means that the students used to solve their vocabulary problems. The students also made use of communication tools such as phone, email and MSN to mediate their vocabulary learning activities. Further, students consulted online dictionaries or resources using the

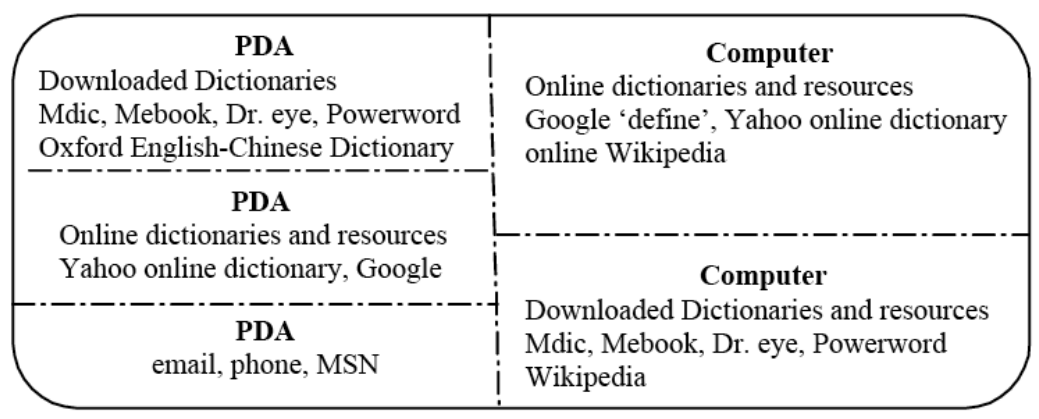

Fig. 13. Integrated uses of the PDA and the computer in incidental vocabulary learning 
PDA or the computer, or accessed the downloaded dictionary or web resources (e.g., Wikipedia) on the computer for achieving deeper understanding of certain words or academic terms. This indicated that students employed an integrated approach to the technology use. They would choose whatever means provided by either the PDA or the computer for the sake of convenience and usefulness to meet their learning needs. The tools on the PDA and the computer complemented each other, though students made more use of the PDA in their incidental vocabulary learning, as was described from the research findings. These integrated uses are shown in Figure 4 (the dotted lines in this figure refer to the free flow of different uses of the technological tools in context).

\subsection{The two-way shaping processes}

Based on the research findings, it is noted that students adapted their use of the tools on the PDA, sometimes together with the computer, to their incidental vocabulary activities. These learning activities were not only situated in a particular context in relation to time and place, but were also influenced by other factors such as individual student needs, motivation, other people, institution, and other technologies (Sharples, Corlett \& Westmancott, 2002). These factors 'shape the context in the first place and subsequently the learning that occurs' (Merriam, 2001:96). Different students adopted different learning strategies and made vocabulary learning activities happen in different situations, as also indicated in Laufer and Hill's (2000) research study, though similarities did exist.

Some of the students used to have a handheld electronic dictionary, a paper dictionary, or a computer for incidental vocabulary learning. After they were provided with the PDA, it changed their vocabulary learning 'routines'. They made use of the downloaded dictionaries on their PDAs most often, due to its accessibility (Crowe \& van't Hooft, 2006; Kukulska-Hulme, 2007), and never used a hardcopy dictionary throughout this one-year research study. In the meantime, students' use of downloaded dictionaries on the PDA induced some other learning activities in pursuit of deeper understanding of the vocabulary (Hill \& Laufer, 2003) in terms of online explorative learning activities using a PDA or a computer. This enhanced opportunities for learning as opposed to simply the referential use of the downloaded dictionaries on the PDA. The capturing capability of the PDA such as note-taking and picture-taking, and connectivity capability in terms of email, phone and MSN, created more constructive, reflective and conversing learning opportunities. These learning activities encouraged students to make more flexible,

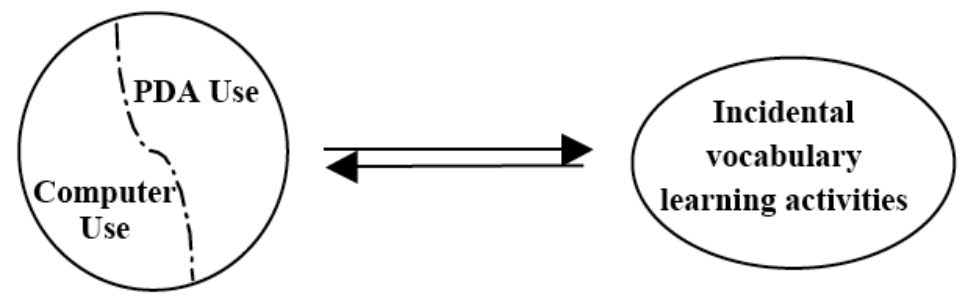

Fig. 14. Integrated uses of the PDA and the computer in incidental vocabulary learning 
creative and effective use of both the PDA and computer technologies.

Just as Waycott (2005) posited a two-way process of tool appropriation and tool mediation in adult workers' everyday practice and tool use, this research study proposed a two-way process of students' integrated technology use (the tools on the PDA and the computer) and their incidental vocabulary learning activities (see Figure 14).

\section{Conclusions}

This research study examined undergraduate EFL students' use of dictionaries and other uses of the PDA to enhance their incidental vocabulary learning in pursuit of their undergraduate studies at an EMI university. In general, the students' attitude towards the technology use was positive. Their experiences in using the tools on the PDA enhanced and extended the way they learned vocabulary in three aspects. Firstly, students did not restrict themselves to making only a referential use of the PDA for their vocabulary learning, they also employed various tools on the PDA for data collection, situated, constructive, reflective, explorative, and conversing uses. Secondly, students made integrated use of the tools on the PDA and the computer. They not only used downloaded dictionaries on the PDA, but also made use of the connectivity tools of internet access to online dictionaries, email, phone and MSN for vocabulary learning purposes. Computer tools were adopted in some situations to accomplish effective technology mediated learning activities. Thirdly, students' uses of the PDA, together with other technology, were not fixed but adaptable and dynamic in the learning processes. These learning activities further drove students to make more creative integrated technology uses. Students' uses of the technologies, therefore, shaped the vocabulary learning activities, and vice versa.

This three-case study is limited in its capacity for generalization, especially as the cases were chosen from highly motivated technology users. Nevertheless, the research indicates that the PDA can be used in more flexible, novel and extended ways for EFL vocabulary teaching and learning in higher education. It is hard to predict what mobile users will choose to do as the highly personal and portable nature of mobile devices makes unexpected things more likely to happen (Kukulska-Hulme, 2007). However, students' learning needs that motivate mobile technology uses, and contextual factors such as time, place, institution, other people and other technologies, have to be investigated before the adoption of a pedagogy relating to mobile technology. It is not the technology itself, but the students' use of the technology that can change learning practices.

The challenge of further mobile technology systems is 'not to provide information any time and anywhere, but to say the right thing at the right time in the right way to the right person' (Fischer \& Konomi, 2007:347).

\section{Acknowledgement}

The authors wish to express their appreciation to the anonymous reviewers for their insightful comments on an earlier draft of this paper, and the participants of the study for their support and cooperation in the research process. The research study was funded 
by a Small Project Fund and Faculty Research fund at Faculty of Education, the University of Hong Kong.

\section{References}

Bourner, T. (2003) Assessing reflective learning. Education \& Training, 45(5): 267-272.

Chen, C.-M. and Chung, C.-J. (2008) Personalized mobile English vocabulary learning system based on item response theory and learning memory cycle. Computers \& Education, 50(1): 77-90.

Clough, G., Jones, A. C., McAndrew, P. and Scanlon, E. (in press) Informal learning with PDAs and smartphones. Journal of Computer Assisted Learning.

Crowe, A. and van't Hooft, M. (2006) Technology and the prospective teacher: Exploring the use of the TI-83 handheld devices in social studies education. Contemporary Issues in Technology and Teacher Education, 6(1): 99-119.

Fischer, G. and Konomi, S. (2007) Innovative socio-technical environments in support of distributed intelligence and lifelong learning. Journal of Computer Assisted Learning, 23(4): 338-350.

Grabe, W. and Stoller, F. (1997) Reading and vocabulary development in a second language: A case study. In: Coady, J. and Huckin, T. (eds.) Second language vocabulary acquisition. Cambridge: Cambridge University Press, 98-122.

Gu, Y. (2003) Fine brush and freehand: The vocabulary-learning art of two successful Chinese EFL learners. TESOL Quarterly, 37(1): 73-104.

Hill, M.M. (1996) What's in a word? Enhancing English vocabulary development by increasing learner awareness. In: Storey, P., Berry, V., Bunton, D. and Hoare, P. (eds.) Issues in Language in Education. Hong Kong: Hong Kong Institute of Education, 179-190.

Hill, M. and Laufer, B. (2003) Type of task, time-on-task and electronic dictionaries in incidental vocabulary acquisition. International Review of Applied Linguistics in Language Teaching, 41(2): 87-106.

Hodder, I. (2000) The interpretation of documents and material culture. In: Denzin, N. K. and Lincoln, Y. S. (eds.) Handbook of qualitative research (2nd ed.). Thousand Oaks, Calif.: Sage Publications, 703-716.

Huang, H.-T. (2007) Vocabulary learning in an automated graded reading program. Language Learning \& Technology, 11(3): 64-82.

Huckin, T. and Coady, J. (1999) Incidental vocabulary acquisition in a second language: A review. Studies in Second Language Acquisition, 21(2): 181-193.

Hulstijn, J. H., Hollander, M. and Greidanus, T. (1996) Incidental vocabulary learning by advanced foreign language students: The influence of marginal glosses, dictionary use, and reoccurrence of unknown words. Modern Language Journal, 80(3): 327-339.

Jonassen, D. H., Hernandez-Serrano, J. and Choi, I. (2000) Integrating constructivism and learning technologies. In: Spector, J. M. and Anderson, T. M. (eds.) Integrated and holistic perspectives on learning, instruction and technology: understanding complexity. Dordrecht: Kluwer Academic Publishers, 103-128.

Jonassen, D. H., Howland, J., Moore, J. and Marra, R. M. (2003) Learning to solve problems with technology: a constructivist perspective (2nd ed.). Upper Saddle River, N.J.: Merrill Prentice Hall.

Klopfer, E., Squire, K. and Jenkins, H. (2002) Environmental detectives PDAs as a window into a virtual simulated world. In: Milrad, M., Hoppe, U. and Kinshuk (eds.) Proceedings of the international workshop on wireless and mobile technologies in education. Växjö, Sweden: The Institute of Electrical and Electronics Engineers, Inc., 95-98.

Kukulska-Hulme, A. (2007) Mobile usability in educational contexts: What have we learnt? 
International Review of Research in Open and Distance Learning, 8(2). http://www.irrodl.org/index.php/irrodl/article/view/356/907

Lai, C.-H., Yang, J.-C., Chen, F.-C., Ho, C.-W. and Chan, T.-W. (2007) Affordances of mobile technologies for experiential learning: the interplay of technology and pedagogical practices. Journal of Computer Assisted Learning, 23(4): 326-377.

Lantolf, J. P. (2000) Sociocultural theory and second language learning. Oxford, U.K.: Oxford University Press.

Laufer, B. (1992) How much lexis is necessary for reading comprehension? In: Arnaud, L. and Bejoint, H. (eds.) Vocabulary and Applied Linguistics. London: Macmillan, 126-132.

Laufer, B. and Hill, M. (2000) What lexical information do L2 learners select in a CALL dictionary and how does it affect word retention? Language Learning \& Technology, 3(2): 5876.

Maxwell, J. A. (1996) Qualitative research design: an interactive approach. Thousand Oaks, Calif.: Sage Publications.

Merriam, S. B. (1998) Qualitative research and case study applications in education (2nd ed.). San Francisco, Calif.: Jossey-Bass Publishers.

Merriam, S. B. (2001) Andragogy and self-directed learning: Pillars of adult learning theory. New Directions for Adult and Continuing Education, 89: 3-14.

Nakata, T. (2008) English vocabulary learning with word lists, word cards and computers: implications from cognitive psychology research for optimal spaced learning. ReCALL, 20(1): $2-30$.

Nation, I. S. P. (2001) Learning vocabulary in another language. Cambridge: Cambridge University Press.

Nesi, H. and Haill, R. (2002) A study of dictionary use by international students at a British university. International Journal of Lexicography, 15(4): 277-305.

Nunan, D. (1992) Research methods in language learning. Cambridge: Cambridge University Press.

Patten, B., Arnedillo-Sanchez, I. and Tangney, B. (2006) Designing collaborative, constructionist and contextual applications for handheld devices. Computers \& Education, 46(3): 294-308.

Patton, M. Q. (1990) Qualitative evaluation and research methods (2nd ed.). Newbury Park, Calif.: Sage Publications.

Roschelle, J., Sharples, M. and Chan, T. W. (2005) Introduction to the special issue on wireless and mobile technologies in education. Journal of computer assisted learning, 21(3): 159-161.

Savenye, W. C. and Robinson, R. S. (2004) Qualitative research issues and methods: An introduction for educational technology. In: Jonassen, D. H. (ed.) Handbook of research on educational communications and technology. Mahwah, N.J.: Lawrence Erlbaum, 10211043.

Sharples, M., Corlett, D. and Westmancott, O. (2002) The design and implementation of a mobile learning resource. Personal and Ubiquitous Computing, 6: 220 - 234.

Shih, Y. E. and Mills, D. (2007) Setting the new standard with mobile computing in online learning. International Review of Research in Open and Distance Learning, 8(2).

Song, Y. (in press) SMS enhanced vocabulary learning for mobile audiences. International Journal of Mobile Learning and Organization.

Stockwell, G. (2007) Vocabulary on the move: Investigating an intelligent mobile phone-based vocabulary tutor. Computer Assisted Language Learning, 20(4): 365-383.

Swan, K., van't Hooft, M., Kratcoski, A. and Unger, D. (2005) Uses and effects of mobile computing devices in K-8 classrooms. Journal of Research on Technology in Education, 38(1): 99-112.

Thornton, P. and Houser, C. (2005) Using mobile phones in English education in Japan. Journal of Computer Assisted Learning, 21(3): 217-228. 
Waycott, J. (2005) Appropriating tools and shaping activities: The use of PDAs in the workplace. In: Hamill, L. and Amparo, L. (eds.) Mobile world: past, present and future. London; New York: Springer, 119-139.

Yin, R. K. (2003) Applications of case study research (2nd ed.). Thousand Oaks: Sage Publications. 